\title{
A REVISTA UNITAS COMO UMA ESTRATÉGIA PEDAGÓGICA: A UNIFICAÇÃO DA AÇÃO DO CLERO NO RIO GRANDE DO SUL/BRASIL
}

\section{THE JOURNAL UNITAS AS AN EDUCATIONAL STRATEGY: THE UNIFICATION OF THE CLERGY'S ACTION IN RIO GRANDE DO SUL / BRAZIL}

\author{
LEON, Adriana Duarte \\ adriana.adrileon@gmail.com \\ IFSUL - Instituto Federal Sul-Rio-Grandense
}

RESUMO Este trabalho analisa a revista Unitas como um mecanismo de unificação do clero na década de 1930, no RS/Brasil. O impresso era uma publicação da arquidiocese de PoA e distribuído em várias cidades do estado; sendo composto basicamente por textos, ilustrações, conteúdo denso e específico. A metodologia adotada no trabalho privilegia a análise qualitativa e o diálogo com a produção bibliográfica sobre o tema. A revista apresenta um leitor implícito, vinculado à estrutura da Igreja e integrante do quadro eclesiástico; o material publicado no impresso ratifica os pressupostos do catolicismo e contempla a ideia de recatolização do Brasil. Dentre as ações presentes no impresso, nota-se a investida em unificar a prática do clero e a divulgação de um ideário de educação católica.

Palavras-chave: Igreja Católica, imprensa, estratégia pedagógica, ideário educacional.

ABSTRACT This paper examines how the Catholic Journal Unitas was consolidated as a unifying mechanism of the clergy in the 1930s in the state of Rio Grande do Sul, Brazil. Unitas was a publication of the Archdiocese of Porto Alegre and distributed in a number of cities in the state; It was basically composed of texts, some illustrations, dense and specific content. The methodology privileges the qualitative analysis of the journal and a dialogue with the literature. The journal implicitly features a reader, linked to the structure of the Church and its members; the material published confirms the assumptions of Catholicism and the idea of reintroduction of a catholic doctrination in Brazil. Among the various actions in the printed, it is clear the intention in unifying the practice of clergy and the dissemination of Catholic education tenets.

Keywords: Catholic Church, Catholic Press, educational strategy, educational ideas.

\section{INTRODUÇÃO}

Este trabalho visa analisar como a revista católica Unitas - Revista Eclesiástica da Arquidiocese de Porto Alegre - se consolidou como um mecanismo de unificação do clero na década de 1930, no estado do Rio Grande do Sul/Brasil. O impresso era uma publicação da arquidiocese de Porto Alegre e distribuído em várias das cidades do estado; era composto basicamente por textos, poucas 
Atos de Pesquisa em Educação - ISSN 1809-0354

Blumenau, v. 12, n.2, p.512- 530, mai./ago. 2017

DOI: http://dx.doi.org/10.7867/1809-0354.2017v12n2p512-530

ilustrações, conteúdo denso e específico. A revista apresenta um leitor implícito, vinculado à estrutura interna da Igreja e integrante do quadro eclesiástico. Cabe destacar que o material publicado no impresso ratifica os pressupostos do catolicismo e contempla a ideia de recatolização do Brasil.

Também cabe relembrar que a primeira constituição do governo republicano estabeleceu a laicidade do Estado brasileiro e tal ação estimulou a Igreja Católica a reorganizar-se internamente a fim de garantir espaço social. O movimento católico estabeleceu nacionalmente diversas iniciativas no sentido de ampliar o espaço de intervenção. O cardeal D. Sebastião Leme, arcebispo do Rio de Janeiro na década de 1930 e amigo de João Becker, Arcebispo de Porto Alegre no mesmo período, foi uma das lideranças importantes deste movimento e reivindicava a recatolização do Brasil, em acordo com os princípios da Romanização do Catolicismo.

O movimento de Romanização do Catolicismo era uma forma de restabelecer no cotidiano dos sujeitos a prática dos sacramentos e a hierarquia da Igreja Católica. No Brasil, a romanização do catolicismo expressou-se no movimento que ficou conhecido como recristianização ou recatolização do país.

Diversos impressos fazem parte da história do Brasil no início do século XX, dentre eles nota-se o aumento na produção de impressos católicos como uma estratégia utilizada pela Igreja no intuito de ampliar sua intervenção na sociedade. A revista Unitas faz parte desse quadro e contribui estrategicamente na organização do clero no estado do Rio Grande do Sul. Metodologicamente, entende-se aqui o impresso como parte da sociedade que o fabricou, impregnado dos conflitos e das disputas de sua época. Nesta lógica, a Unitas foi uma estratégia, como sugere Certeau (2011), utilizada em prol da recatolização do país.

A articulação da Igreja Católica junto ao debate educacional no sul do Brasil enfrenta a influência das ideias positivistas, muito presentes no contexto local. $\mathrm{Na}$ primeira metade da década de 30 do século XX, o estado do Rio Grande do Sul estava dividido em quatro circunscrições eclesiásticas ${ }^{1}$ : diocese de Pelotas, diocese de Santa Maria, diocese de Uruguaiana e arquidiocese de Porto Alegre. Junto à

1As informações referentes à estrutura eclesiástica da Igreja Católica no Rio Grande do Sul foram acessadas através do setor de arquivo da arquidiocese de Porto Alegre. 
Atos de Pesquisa em Educação - ISSN 1809-0354

Blumenau, v. 12, n.2, p.512- 530, mai./ago. 2017

DOI: http://dx.doi.org/10.7867/1809-0354.2017v12n2p512-530

arquidiocese estava situado o Arcebispo e junto a cada uma das dioceses estava situado o respectivo bispo responsável. A divisão do estado nessas quatro grandes regiões eclesiásticas ocorreu em 1910 pela bula "Praedecessorum nostrorum", de $\mathrm{PIO} \mathrm{X}^{2}$. No período anterior ${ }^{3}$ à Bula, a província do Rio Grande do Sul, na estrutura da Igreja Católica, estava subordinada ao Rio de Janeiro. Havia um vigário geral em Porto Alegre e vigários esporádicos em algumas paróquias. De forma geral, a gerência da Igreja sobre as paróquias era muito limitada ${ }^{4}$. A nova organização possibilitou certa autonomia para a Igreja no estado, bem como dinamizou as ações nas dioceses, devido à presença dos bispos responsáveis. Tal divisão vigorou até o final de 1934, data da criação da diocese de Caxias do Sul. Ainda no final da década de 1930, foi criada a diocese de Vacaria. A partir de 1951, outras divisões ocorreram; no entanto, não serão abordadas aqui ${ }^{5}$.

Dentre as diversas ações presentes no impresso, nota-se a investida em unificar a prática do clero rio-grandense e a divulgação de um ideário de educação católica. O debate educacional ganha destaque neste período, pois é um dos itens em disputa pela Igreja Católica no processo constituinte de 1933. Pode-se perceber a corporificação das reivindicações em torno deste ponto, considerando algumas estratégias explicitadas na revista.

Dom João Becker, arcebispo metropolitano, era o responsável pela publicação da revista Unitas e afirmava a necessidade de unir o clero em prol de uma única causa. Observava que os padres que atuavam no Rio Grande do Sul eram oriundos de lugares distintos, alguns imigrantes e com cultura muito diversa; cumula-se a isso, o fato de atuarem em regiões distantes da arquidiocese. Sendo assim, a

2De acordo com Tambara (2005), uma das formas mais eficazes e tradicionais de comunicação da Igreja Católica com seus fiéis foi a epistolar. Nesta área, destacam-se, na hierarquia da Igreja, as encíclicas papais, como é o caso da bula 'Praedecessorum nostrorum', de São Pio X, e as cartas pastorais episcopais.

3 O primeiro Bispo de Porto Alegre, Dom Feliciano José Rodrigues Prates (1853-1858), foi um dos bispos que contribuía com o movimento de reforma da Igreja Católica no Brasil. Ao ser designado para assumir o bispado de Porto Alegre, intensifica a organização da Igreja Católica no Estado: constrói cemitérios, estabelece o bispado, cria novas paróquias e preocupa-se com a formação do clero.

4Ver Rubert (1994).

5Tal divisão aparece de forma detalhada na revista católica Unitas, ano de 1932, número referente aos meses de junho e julho. 
Atos de Pesquisa em Educação - ISSN 1809-0354

Blumenau, v. 12, n.2, p.512- 530, mai./ago. 2017

DOI: http://dx.doi.org/10.7867/1809-0354.2017v12n2p512-530

produção de uma revista era salutar para a organização da Igreja no estado. A Unitas era o órgão oficial de divulgação da arquidiocese de Porto Alegre; informava e formava o clero sobre as questões da arquidiocese e da organização da Igreja Católica no mundo; foi um eficiente mecanismo pedagógico; possibilitou a unificação das práticas do clero e a intervenção organizada junto a questões polêmicas do período. Os temas anunciados na imprensa católica estavam em pauta e em disputa na sociedade brasileira no início do século vinte, a Igreja assumia posição junto a essas questões e disputava tal posição por meio de vários espaços, dentre eles a imprensa.

\section{A AMPLIAÇÃO DA IMPRENSA CATÓLICA}

A intensificação do investimento católico na imprensa é motivada pelo combate à ideia de um Estado laico presente na primeira constituição republicana e vigente até a década de 1930. Na tentativa de recatolizar o Brasil, a Igreja Católica reorganiza-se internamente e estabelece novas frentes de atuação, com o objetivo de manter-se como espaço de referência religiosa e cultural no país. Para viabilizar tal intervenção foi necessária a rearticulação dos discursos e das práticas, em que a Igreja buscou se adaptar ao processo de modernização como estratégia de disputa pelo espaço que considerava perdido ou em disputa.

A imprensa se constituiu em um movimento de larga escala que alterou a forma de organização da vida social brasileira. A análise dos impressos se consolida como "uma janela aberta" (GINZBURG, 2011) que pode anunciar o cenário político, os movimentos organizados, os grupos em emergência e as principais polêmicas e disputas do país. $O$ início do século $X X$ estabelece a passagem da pequena imprensa para a grande imprensa, caracterizada pela substituição dos pequenos jornais, feitos artesanalmente em tipografias, pelos jornais produzidos nas empresas jornalísticas, com equipamento gráfico potente, produção em grande escala e de circulação ampla. Sodré (1977), ao tratar da história da imprensa, destaca que esse momento foi um marco na produção de impressos no país, pois muitos jornais regionais e locais não conseguiram concorrer com o moderno equipamento que 
Atos de Pesquisa em Educação - ISSN 1809-0354

Blumenau, v. 12, n.2, p.512- 530, mai./ago. 2017

DOI: http://dx.doi.org/10.7867/1809-0354.2017v12n2p512-530

possibilitava a produção dos jornais em larga escala e desapareceram ${ }^{6}$.

A Igreja Católica estabelece sua intervenção englobando a imprensa e articula uma estratégia para esse setor que contempla a criação da Liga da Boa Imprensa, com a organização de um grupo de jornalistas católicos e uma forte campanha em prol da assinatura de revistas e jornais. A imprensa católica reivindica um espaço junto às famílias e consolida uma estratégia discursiva que a caracteriza como leitura obrigatória: "Nenhuma família católica sem jornal católico" (UNITAS, 1930, n. 2, p. 138).

Lustosa (1983), ao tratar dos impressos católicos, afirma que "foram um canal privilegiado, utilizado bem ou mal pela hierarquia e pelos católicos, para defender a fé e os costumes, para reivindicar direitos, para lutar contra os adversários e, em uma palavra, para formar e informar." (LUSTOSA, 1983, p. 8). A logística estabelecida na produção de jornais católicos foi estimular a produção de jornais estaduais e/ou regionais e subsidiar teórica e estruturalmente esses impressos por meio da Boa Imprensa. Destacam-se alguns indicadores sobre a pretensão de produzir um diário católico nacional ${ }^{7}$ que, embora tenha feito parte do debate da Liga da Boa Imprensa em alguns momentos, não adquiriu materialidade.

No que se refere à produção de revistas, a Igreja Católica mantinha, em âmbito nacional, algumas publicações que circulavam de forma mais abundante na região central do país, constituindo-se a cidade do Rio de Janeiro como espaço prioritário para a produção e a circulação desse material. Dada a necessidade de ampliar a produção e a circulação da imprensa católica no Brasil, a Igreja estimula a publicação de impressos regionais, possibilitando a ampliação da pauta nacional, bem como o atendimento às particularidades locais. Tal estratégia, ao mesmo tempo em que implementa um projeto de abrangência nacional, torna os impressos

6De acordo com Sodré (1977), o jornal, como empreendimento individual, diminui drasticamente com o crescimento da imprensa empresarial e, gradativamente, os pequenos jornais, vinculados a grupos de menor expressão, deixam de fazer parte do cotidiano do país.

7 De acordo com Lustosa (1983), a ideia de um diário católico não teve condição de ser levada adiante, embora tenham sido feitas algumas tentativas no sentido de transformar os diários locais, como O São Paulo - 1906, em diário nacional; no entanto, tais iniciativas não deram certo, pois não se caracterizavam no conteúdo ou na circulação como uma potência nacional. 
Atos de Pesquisa em Educação - ISSN 1809-0354

Blumenau, v. 12, n.2, p.512- 530, mai./ago. 2017

DOI: http://dx.doi.org/10.7867/1809-0354.2017v12n2p512-530

católicos mais interessantes para o leitor que vê neles sua realidade retratada.

Com o objetivo de intervir no espaço público e propiciar opções de leitura com abrangência nacional, a Igreja Católica mantinha a Revista $A$ Ordem, órgão do Centro Dom Vital; o Boletim da Associação dos Professores Católicos, que começou a circular em 1932 e, em 1934, foi substituído pela Revista Brasileira de Pedagogia ${ }^{8}$, que se propunha a discutir as diversas questões relacionadas ao ensino e a ampliar o debate acerca dos pressupostos anunciados na encíclica Divini Illius Magistri, de $\mathrm{PIO} X \mathrm{XI}$.

Além das produções nacionais, a Igreja estimulava a publicação de impressos regionais com o objetivo de ampliar o diálogo da instituição com a sociedade. Tal orientação propiciou o surgimento de diversos impressos católicos no Brasil. Em conformidade com essa estratégia, no Rio Grande do Sul, foi produzida uma gama variada de impressos, dentre eles a revista Unitas, os quais permitem demonstrar e analisar a ampliação da imprensa católica no país.

Preservada a característica didático-pedagógica, os jornais católicos, no início do século $X X$, se pareciam pelo estilo e conteúdo. Tal identidade era possível pela existência do Centro da Boa Imprensa e da Liga da Boa Imprensa. O Centro tinha como função auxiliar na criação de jornais ou revistas e na manutenção de seu conteúdo; a Liga auxiliava no suporte administrativo e financeiro. Ainda movendo seus esforços sobre a imprensa católica, estava a Associação da Boa Imprensa, que reunia jornalistas católicos com o objetivo de pensar estratégias para ampliar as intervenções no setor.

Diversos trechos ilustram a ação da Boa Imprensa, cita-se aqui como exemplo a publicação de um trecho, sob o titulo "O programa do eleitor católico" que aparece repetidamente em vários jornais católicos e explicita uma orientação clara sobre como cada cidadão deveria realizar o exercício do voto.

Programa do Eleitor Católico

1. Ser eleitor independente, ou filiar-se a um partido que, além de outros

8 Sobre o Boletim da Associação dos Professores Católicos e a Revista Brasileira de Pedagogia, ver Sgarbi (1997) e Lopes (2003). 
objetivos patrióticos, pleiteie:

$1^{\circ}$ Deus na constituição e um dia oficial de ação de graças;

$2^{\circ}$ Ensino facultativo de religião nas escolas;

$3^{\circ}$ Repulsa ao divórcio;

$4^{\circ}$ Registro do casamento religioso para efeitos civis;

$5^{\circ}$ Descanso dominical;

$6^{\circ}$ Honestidade administrativa;

$7^{\circ}$ Unidade do Brasil e distribuição equitativa das rendas Federais, em benefício dos diversos Estados;

$8^{\circ}$ Desdobramento e coordenação das vias de penetração, convergindo para uma via de ligação interna entre o norte e o sul do Brasil;

$9^{\circ}$ Proteção às classes agrícolas e operárias;

$10^{\circ}$ Fomento à produção e à exportação: e repressão do protecionismo exagerado;

$11^{\circ}$ Completa isenção de impostos para os gêneros de primeira necessidade.

2. Formar juntas paroquiais consultivas, para orientação da consciência eleitoral católica, e seleção de candidatos.

3. Em qualquer hipótese, negar sempre seu voto a um candidato ímpio ou desonesto ou absorvente.

Nota: pede-se a todos os jornais católicos transcreverem este programa.

(A PALAVRA, 10/04/1932, p. 2)

O trecho acima foi publicado em diversos impressos católicos no Rio Grande do Sul e indica a organicidade da Boa Imprensa no estado. Cada meio de comunicação impressa atinge um público leitor específico. Assim, ao imprimir o mesmo texto em diversos impressos, a Boa Imprensa pretende estabelecer a unidade da ação católica em diferentes setores da sociedade.

De acordo com Dutra (2005), os jornais ou os almanaques atingem um público leitor mais amplo, considerando que o acesso a cada exemplar é facilitado pelo baixo custo e as notícias são apresentadas de forma objetiva, facilitando a apreensão do leitor. São caracterizados como literatura de fácil apreensão, pela linguagem simplificada, conteúdo ameno, variado e, sobretudo, barato.

Os impressos também funcionam como espaços de sociabilidade, que projetam sujeitos, ideias, valores e a própria instituição. Dom João Becker, arcebispo de Porto Alegre, é uma figura presente na Unitas e consolida-se, neste período, como uma das lideranças católicas no estado. Micelli (1977) observa que, no início do século $\mathrm{XX}$, os impressos se constituíram na principal instância de produção 
Atos de Pesquisa em Educação - ISSN 1809-0354

Blumenau, v. 12, n.2, p.512- 530, mai./ago. 2017

DOI: http://dx.doi.org/10.7867/1809-0354.2017v12n2p512-530

cultural e forneciam a maior das gratificações no que se refere à posição intelectual. Considerando essa lógica, é comum observar os intelectuais e as lideranças católicas presentes nos impressos.

Dom João Becker publica na revista da Arquidiocese de Porto Alegre e contribui com o conjunto dos impressos no Rio Grande do Sul, mais acentuadamente com o jornal Estrella do Sul, pois é uma produção do Centro da Boa Imprensa, localizada na capital e sob influência direta do seu bispado. $O$ reconhecimento público de Dom João Becker é resultado da posição que ocupa na hierarquia da Igreja Católica e das suas aparições no espaço público, dentre os quais se destaca a imprensa.

É interessante ponderar que a imprensa está atrelada à constituição de um novo espaço público que projeta os valores da modernidade relacionados à ideia de progresso e difusão da ciência. A produção impressa de circulação periódica se consolida como um eficiente espaço de construção da imagem pública, pois possibilita o acesso ao cotidiano dos sujeitos que ocupam espaços importantes na hierarquia política do período. O "surgimento da imprensa no Brasil acompanha e vincula-se às transformações nos espaços públicos, à modernização política e cultural de instituições, ao processo de independência e de construção do Estado nacional" (Morel; Barros, 2003, p. 7).

Dom João Becker é uma liderança da Igreja Católica que aparece constantemente na imprensa católica do Rio Grande do Sul; utiliza-se estrategicamente deste meio de comunicação para ratificar a posição que ocupa na hierarquia da instituição e para promover a publicização de suas orientações. Notase, na Unitas e no Estrella do Sul, na transcrição de trechos de suas cartas pastorais, o júbilo manifestado nas aparições públicas e a publicação de textos por ele assinados, orientando os leitores sobre as questões práticas do dia a dia.

A imprensa católica busca ser um canal de comunicação entre a lgreja e os cidadãos. Embora às vezes se apresentasse de forma mais leve, não perdia de vista os objetivos que norteavam sua existência. "A imprensa católica tem por fim, no dizer 
Atos de Pesquisa em Educação - ISSN 1809-0354

Blumenau, v. 12, n.2, p.512- 530, mai./ago. 2017

DOI: http://dx.doi.org/10.7867/1809-0354.2017v12n2p512-530

do Santo Padre, cooperar com todo o zelo e com toda a operosidade para propagar o reino de Deus e a salvação das almas. Esta deve ser a aspiração do jornal católico!" (A PALAVRA, 22/01/33, p. 1).

\section{IMPRESSOS CIRCULANTES NO RIO GRANDE DO SUL EM 1930}

A análise dos impressos católicos ${ }^{9}$ dá visibilidade a diversas iniciativas da Igreja, visando à modernização de sua mensagem e dos meios para fazê-la chegar até os fiéis. A produção de impressos é uma iniciativa nacional da instituição que estabelece um diálogo eficaz com o leitor, faz parte do movimento de recatolização da Igreja Católica e pretende estabelecer o impresso como mais um apóstolo em prol do catolicismo.

A imprensa também pode ser considerada como um apóstolo, porquanto ela tem entrada nos lares, nas sociedades, e até nas casas de correção; neste último caso, quando para ali é encaminhado por uma boa alma, e em outros tantos lugares onde seria impossível a presença de uma pessoa para neles lançar a semente do bem. (A PALAVRA, 01/02/1930, p.3).

No que se refere aos tipos de impressos católicos localizados no Rio Grande do Sul, observa-se duas modalidades de imprensa periódica, os jornais e as revistas. Embora apresentem características distintas, essas duas modalidades apresentam similitudes no que se refere à proposição de um projeto político para o Brasil.

De acordo com Lustosa (1983, p. 11), “a imprensa católica é uma espécie de termômetro da vitalidade da comunidade eclesial em cada uma das épocas históricas, através de uma leitura crítica dos periódicos se toma o pulso da atuação da Igreja." No Rio Grande do Sul, foram criados diversos jornais e revistas no início do século XX e seguem a lógica do movimento de reorganização da Igreja Católica no Brasil. Circularam em regiões importantes do estado e indicam representações relevantes sobre questões polêmicas do período. O quadro abaixo indica a diversidade e a organização da imprensa católica no estado.

9 Os impressos propostos como fontes para esta pesquisa estão subdivididos em jornais e revistas, embora tenhamos consciência de que o termo "impressos" é mais amplo e se refere a todo material escrito e impresso. 
Atos de Pesquisa em Educação - ISSN 1809-0354

Blumenau, v. 12, n.2, p.512- 530, mai./ago. 2017

DOI: http://dx.doi.org/10.7867/1809-0354.2017v12n2p512-530

Quadro 1 - Levantamento dos impressos circulantes no Rio Grande do Sul

\begin{tabular}{|c|c|c|c|c|c|c|c|c|c|c|}
\hline Nome & Jornal & Revista & formato & Semanal & $\begin{array}{l}\text { Mensal } \\
\text { Bim. } \\
\text { Trim. }\end{array}$ & $\begin{array}{l}\text { N. de } \\
\text { pág. }\end{array}$ & Cidade & Produção & Acervo & $\begin{array}{c}\text { Períod } \\
0\end{array}$ \\
\hline Estrella do Sul & $x$ & & A3 & $x$ & & 4 & PoA & $\begin{array}{l}\text { Boa } \\
\text { Imprensa }\end{array}$ & AHCMPA & $\begin{array}{l}1923 \\
1939\end{array}$ \\
\hline Unitas & & $x$ & A5 & & $x$ & $\begin{array}{c}50 \\
a \\
130\end{array}$ & PoA & $\begin{array}{l}\text { Arquidiocese } \\
\text { de PoA }\end{array}$ & AHCMPA & $\begin{array}{l}1913 \\
1946\end{array}$ \\
\hline A palavra & $\mathrm{x}$ & & A3 & $x$ & & $\begin{array}{l}4 \\
a \\
8\end{array}$ & Pelotas & $\begin{array}{l}\text { Diocese de } \\
\text { Pelotas }\end{array}$ & $\begin{array}{l}\text { Mitra } \\
\text { diocesana } \\
\text { Pelotas }\end{array}$ & $\begin{array}{l}1912 \\
1959\end{array}$ \\
\hline IL Colono & \multirow{2}{*}{$x$} & & \multirow{2}{*}{ A3 } & \multirow{2}{*}{$x$} & & \multirow{2}{*}{4} & \multirow{2}{*}{$\begin{array}{c}\text { Caxias do } \\
\text { Sul }\end{array}$} & \multirow{2}{*}{$\begin{array}{c}\text { Caxias do } \\
\text { Sul }\end{array}$} & \multirow{2}{*}{ MUSCAP } & $\begin{array}{l}1912 \\
1917\end{array}$ \\
\hline $\begin{array}{l}\text { Estaffetta } \\
\text { Rio-grandense }\end{array}$ & & & & & & & & & & $\begin{array}{l}1918 \\
1940\end{array}$ \\
\hline A Rainha & & $x$ & A5 & & $x$ & $\begin{array}{c}+ \text { ou - } \\
20\end{array}$ & $\begin{array}{l}\text { Santa } \\
\text { Maria }\end{array}$ & Santa Maria & $\begin{array}{l}\text { Acervo } \\
\text { Padres } \\
\text { Palotinos }\end{array}$ & $\begin{array}{l}1923 \\
\text { Atual }\end{array}$ \\
\hline
\end{tabular}

Fonte: Revista Unitas

Cabe explicitar que não estão representados no quadro acima os jornais de cunho católico, produzidos pelos imigrantes alemães ${ }^{10}$ e circulantes em comunidades específicas. A presença desses impressos é significativa no Estado, mas não foi possível mapeá-los neste momento.

A ampliação da imprensa católica no Brasil dialoga com o esforço da Igreja pelo fortalecimento de suas bases institucionais. Azzi (2008), ao tratar da história da Igreja no Brasil, no início do século XX, afirma que a característica principal do período é o fortalecimento da instituição. Através da organização das paróquias, dos colégios e das dioceses, a "Igreja deseja consolidar o seu enraizamento no solo brasileiro, a fim de manter e preservar os valores tradicionais" (AZZI, 2008, p. 485). $\mathrm{Na}$ realização desta tarefa, a imprensa católica se constituía como uma 'via de entrada' para o catolicismo em espaços desvinculados da instituição e assim

10 Nas colônias de imigrantes alemães circulavam impressos católicos produzidos pelos grupos imigrantes. Embora não tenhamos mapeado esses impressos, nos aproximamos desta produção por intermédio dos estudos de Lúcio Kreutz (1991, 2002, 2007 e 2011). 
Atos de Pesquisa em Educação - ISSN 1809-0354

Blumenau, v. 12, n.2, p.512- 530, mai./ago. 2017

DOI: http://dx.doi.org/10.7867/1809-0354.2017v12n2p512-530

ampliava a base da mesma. Em alguns momentos, a imprensa ganhou status de apóstolo, considerando exatamente a possibilidade de chegar a locais imprevisíveis e improváveis.

O Impresso proposto para este trabalho, como foco de análise, está vinculado de forma explicita à Igreja Católica e dialoga prioritariamente com o clero. Inspirados em Revel (1998), buscamos analisar o impresso, valorizando as migalhas de informação no intuito de compreender de que maneira estes detalhes podem dar acesso a lógicas sociais simbólicas que são dos grupos ou de conjuntos muito maiores.

A revista analisada encontra-se em bom estado de conservação no arquivo da mitra diocesana de Porto Alegre. A motivação metodológica engloba o processo de desmontar e remontar o período, buscando estabelecer conexões que possibilitem entender as estratégias estabelecidas pela Igreja Católica a fim de intervir no espaço social. Observamos, assim como sugere Chartier (1998), alguns elementos da cultura do impresso e identificamos algumas características que dialogam de forma direta com um determinado público leitor. Ao analisar o impresso, percorremos as imagens, os relatos das dioceses, os textos e os anúncios. Tal material nos indicou elementos para constituição de uma identidade sobre os leitores. Cumulam-se aos elementos linguísticos os aspectos editoriais que se relacionam com a tiragem e a distribuição da revista.

Os impressos católicos têm-se mostrado como importante fonte e objeto de pesquisa para a história da educação, pois, segundo Magaldi (2010), ao assumirem um caráter doutrinário, explicitam muito das tensões presentes no projeto católico. Conforme já dito, a imprensa é o meio de comunicação de maior circulação no período; sendo assim, a Igreja estimulava a publicação de impressos regionais com o objetivo de orientar católicos e simpatizantes. A produção da revista Unitas pela arquidiocese de Porto Alegre se consolida neste contexto e sob influência direta de Dom João Becker.

\section{A REVISTA UNITAS E A DIVULGAÇÃO DE UM IDEÁRIO DE EDUCAÇÃO}


Atos de Pesquisa em Educação - ISSN 1809-0354

Blumenau, v. 12, n.2, p.512- 530, mai./ago. 2017

DOI: http://dx.doi.org/10.7867/1809-0354.2017v12n2p512-530

\section{CATÓLICA}

A revista Unitas é uma publicação da arquidiocese de Porto Alegre; de forma geral, apresenta, nas primeiras páginas, uma carta pastoral de Dom João Becker ou informes da Santa Sé; após, informes sobre as paróquias, às vezes informes das dioceses e informes gerais; apresenta uma secção doutrinária que comumente apresenta uma reflexão sobre temas polêmicos.

Na primeira página, a apresentação se repete: Unitas - Revista da província eclesiástica de Porto Alegre - direção Cúria metropolitana. Sua abrangência é maior que a anunciada, pois assume a função de formar o clero espalhado pelo estado do Rio Grande do Sul. O conteúdo da revista é composto por textos longos; comumente publica cartas pastorais e discursos de representantes eclesiásticos; o vocabulário é rebuscado e seletivo, o que nos sugere um leitor acostumado ao mundo da leitura, aos informes do ambiente eclesiástico e conhecedor da hierarquia da Igreja Católica. Nota-se também a publicação dos relatórios das dioceses: Santa Maria, Uruguaiana e Pelotas. Por vezes, em tais relatórios, aparece uma prestação de contas, contendo os valores arrecadados nas dioceses. Esse, entre outros detalhes, sugere que a Unitas tinha como principal público leitor o clero, os integrantes dos grupos religiosos e o laicato intelectualizado, provavelmente vinculado às dioceses.

O primeiro número da revista Unitas foi lançado em 1913, um ano após Dom Becker assumir o cargo de arcebispo metropolitano. A revista, de certa forma, era um item eficiente que compunha a gestão do arcebispo, pois cumpria a função de tornar pública e unificar a orientação estabelecida pelo mesmo. Ela foi mantida ativa até 1946, ano da morte de D. Becker, quando teve interrupção brusca de sua publicação. Ou seja, a ausência de D. Becker - mentor intelectual da revista inviabilizou o periódico por algum tempo. Para fins deste estudo não analisamos os exemplares pós 1946, mas cabe destacar que, em 1947, a Unitas voltou a circular como parte da gestão do Cardeal Alfredo Vicente Scherer, arcebispo titular de Porto Alegre (de 1947 a 1981) e, assim como D. Becker, dirigiu e manteve o boletim Unitas 
Atos de Pesquisa em Educação - ISSN 1809-0354

Blumenau, v. 12, n.2, p.512- 530, mai./ago. 2017

DOI: http://dx.doi.org/10.7867/1809-0354.2017v12n2p512-530

como órgão oficial de divulgação da arquidiocese. ${ }^{11}$

A quantidade de páginas que compunha cada edição da revista Unitas era diversa. Conforme explicitado no quadro acima, encontramos uma variação de página por edição de 50 a 130 páginas. De forma geral, quando ocorria a publicação de uma carta pastoral de D. Becker, a edição se tornava mais extensa. A versão que utilizamos neste trabalho faz parte do arquivo da Mitra Diocesana de Porto Alegre, onde os exemplares da revista estão encadernados por ano de sua publicação; a numeração apresentada é a sequência da encadernação; por esse motivo, as páginas referidas no presente texto podem apresentar uma numeração superior à quantidade de páginas do exemplar específico.

$\mathrm{Na}$ revista referente aos meses de agosto e setembro de 1932, Dom João Becker publica sua vigésima segunda carta pastoral na íntegra sob o título: Os Católicos e a futura constituição. Considerando a data da publicação e o conteúdo, nota-se que a carta faz uma avaliação negativa do período vivenciado pela Igreja e afirma que os católicos têm a possibilidade de reverter tal situação, por meio do voto.

A carta trata basicamente da reforma constituinte e constrói o seu argumento estimulando a participação dos católicos neste processo; faz uma breve retrospectiva sobre as constituições brasileiras, critica o laicismo, convoca os sujeitos a defender o catolicismo, advoga a ideia de uma república católica, afirma a necessidade do ensino religioso nas escolas e destaca as características de um bom político. No item referente 'aos católicos em face à política', Dom Becker convoca de forma explícita os católicos a participarem da política e da organização do Estado.

Das atribuições da religião com referência à política profana e, sobretudo, à política religiosa e eclesiástica resulta que os católicos "têm a obrigação sacrossanta, imposta por Deus, de envidar todos os esforços para que o espírito do evangelho penetre em todas as leis e instituições dos povos". Devemos transfundir a sabedoria e a fortaleza da religião, como um sangue vivificador, nas artérias do Estado. (UNITAS - $22^{\circ}$ Carta Pastoral de D. Becker, ago/set, 1932, p.32).

11 A publicação da revista foi interrompida por algumas vezes após 1981, mas, desde 2014, vem sendo publicada pela arquidiocese de Porto Alegre (RS), estando disponível na página da mesma. 
Atos de Pesquisa em Educação - ISSN 1809-0354

Blumenau, v. 12, n.2, p.512- 530, mai./ago. 2017

DOI: http://dx.doi.org/10.7867/1809-0354.2017v12n2p512-530

A construção discursiva sobre educação, presente nas páginas da Unitas, mantinha o foco central na educação escolar e, nesse sentido, disputava espaço para o catolicismo na escola, defendia a família e os direitos desta instituição na educação da criança, argumento que era apresentado de forma recorrente e buscava justificar a presença do catolicismo nas escolas. "O que se pede é permissão para ensinar a religião de acordo com os desejos dos pais das crianças que frequentam os cursos" (UNITAS, mar/abr, 1931, p. 225).

Embora a construção discursiva utilize a expressão: "o que se pede é permissão para ensinar qualquer religião". Na prática, o retorno do ensino religioso facultativo nas escolas ${ }^{12}$ se consolidaria como o ensino dos princípios do catolicismo, dada a nossa identidade e construção histórica cultural. A investida presente na imprensa é a responsabilização da família pela educação da prole. A escolha por uma educação de qualidade ou sem qualidade é responsabilidade da mesma. A família também é responsabilizada pela atuação do Estado, ou seja, cabe à mesma escolher e pressionar os seus governantes para receber uma educação de qualidade e de acordo com seus princípios.

Os católicos devem ser mais do que nunca verdadeiros apóstolos. É preciso contribuir para a manutenção da ordem pública, para o prestígio do governo estadual e da república, para a estabilidade da família e para a realização das aspirações católicas. (UNITAS, 1931, n.7 e 8, p. 385).

Para ser eficaz no contexto de uma sociedade moderna, a defesa da liberdade de ensino ganhou novos argumentos e exigiu mudanças na estratégia discursiva da instituição. Uma das frentes adotadas foi associar o laicismo à desordem e o catolicismo à ordem, ao progresso e ao desenvolvimento da nação.

O número de outubro de 1933 da revista Unitas faz referência à carta de Becker que pauta o Estado brasileiro e pontua detalhadamente um ideal de Estado em comum acordo com os princípios do catolicismo. A carta está intitulada como 'O

12 Cabe observar que a primeira constituição republicana ao estabelecer o estado laico proibiu a presença do ensino religioso nas escolas públicas. A década de 1930, com a possibilidade da revisão constitucional, marca uma nova disputa em torno de tal tema e a Igreja Católica mobilizase fortemente a favor do retorno do ensino religioso facultativo nas escolas. 


\section{Atos de Pesquisa em Educação - ISSN 1809-0354 \\ Blumenau, v. 12, n.2, p.512- 530, mai./ago. 2017 \\ DOI: http://dx.doi.org/10.7867/1809-0354.2017v12n2p512-530}

Novo Estado Brasileiro'; foi publicada na íntegra na revista e está subdivida nos seguintes tópicos: os momentos históricos; a revolução de 1930 e suas consequências; o dever da igreja na atualidade; a escassez de condutores de homens; a qualidade de condutor do povo; os direitos do homem e os direitos de Deus; a deformação das liberdades públicas; a igreja face às liberdades modernas; a liberdade que a igreja reclama; o valor natural e sobrenatural dos homens; a família e o estado; a voz da etnografia; o estado e o direito dos pais; a necessidade do ensino religioso; o Estado e os princípios da moral; os problemas concretos do Estado; os direitos internacionais do estado; a solução de dúvidas; a finalidade do estatuto; o liberalismo econômico e a intervenção do Estado; a autoridade e a liberdade no Estado; os deveres cívicos; o serviço militar; a comunicação do poder estatal; o novo Estado e a religião; a concentração nacional; a eugenia e o neomalthusianismo; a educação sexual; o estado integral brasileiro e as considerações finais.

Becker faz uma retrospectiva histórica de como foram constituídas as constituições brasileiras; afirma a responsabilidade dos católicos com a nação e com a pátria e convoca todos à reconstituição do país. Afirma que a crise do Estado é um problema contemporâneo e faltam condutores para o povo, trata da educação com foco no ensino religioso, valoriza a família e encerra a carta desejando uma feliz Pátria a todos.

Por isso, teve plena razão o ilustre ministro Osvaldo Aranha quando consagrou esse direito no projeto de lei apresentado, em março de 1933, à comissão encarregada de preparar a futura constituição do país. 'Art. 1 - à união compete promover, orientar e dirigir a instrução em todos os seus graus, primário, secundário e superior. Parágrafo único: - na difusão e manutenção do ensino público, com a União colaboram os estados e os municípios. Art. 11 - aos pais incumbe o dever de assistir o direito natural de educar os filhos, preparando-os no ponto de vista físico, intelectual, moral e social, para as responsabilidades da vida. Parágrafo 1 - o dever de dar instrução aos filhos, podem cumpri-lo os pais, nas escolas públicas, nos estabelecimentos particulares ou no lar doméstico. Parágrafo 2 - ao estado, em colaboração com as iniciativas particulares, incumbe subsidiariamente o dever de assistência e proteção às crianças, física ou moralmente abandonadas'. Este artigo exprime a verdadeira liberdade de ensino. Aos pais compete o ensino dos filhos, escolhendo as escolas e os mestres. $O$ estado auxilia e ministra o ensino aos que assim não possam ser instruídos. (UNITAS, nov. 1933, p. 364) 
Atos de Pesquisa em Educação - ISSN 1809-0354

Blumenau, v. 12, n.2, p.512- 530, mai./ago. 2017

DOI: http://dx.doi.org/10.7867/1809-0354.2017v12n2p512-530

Sobre o Novo Estado Brasileiro, esse estudo corrobora com a afirmação já feita por Corsetti (2007) de que a Unitas apresentava o foco muito claro na educação e na defesa do catolicismo na instituição escolar.

A Igreja Católica contra-atacava, por vários meios, entre os quais estava a utilização da revista oficial da arquidiocese de Porto Alegre, a Unitas, bem como das organizações leigas vinculadas à instituição. Exemplo disso é a defesa de Deus na escola, que permeou o trabalho dessa revista ao longo de todo o período de sua existência, na primeira República (CORSETTI, 2007, p. 300).

A Igreja Católica, representada por Becker, assumiu posição política muito clara, atuou firmemente junto ao processo constituinte e apoiou o governo Vargas na década de 1930.

No pico do Corcovado, em pleno coração da terra de Santa Cruz, erguer-seá, em breve, uma majestosa estátua de Cristo, ao tributo de amor dos católicos brasileiros. Quando despontará o dia em que possamos dizer, olhando para aquela grandiosa imagem: Cristo vence, Cristo reina, Cristo impera no Brasil (UNITAS, jan/fev, 1930, p. 52).

Em um período de reorganização do país, Becker escolheu e apoiou a hegemonia política, no sul ora representada pelo Partido Republicano Riograndense, antes de 1930, e ora representada pelo Partido Republicano Liberal, pós 1930.

\section{CONSIDERAÇÕES FINAIS}

Diversas foram as iniciativas da Igreja para se reorganizar internamente e disputar espaço social no início do século $X X$, no Brasil. Para fins desta análise, destacamos as disputas que apareceram na revista Unitas e traduzem a função pedagógica assumida por esse impresso. Em um contexto de disputa, onde a unificação do discurso era um desafio, a revista Unitas cumpre a função de ser um espaço de formação para o clero e as lideranças da Igreja Católica no Rio Grande do Sul. As cartas pastorais publicadas por Dom João Becker orquestravam a ação do clero e funcionavam como um recurso pedagógico que possibilitava a formação de representantes importantes do clero e do laicato católico. 
Atos de Pesquisa em Educação - ISSN 1809-0354

Blumenau, v. 12, n.2, p.512- 530, mai./ago. 2017

DOI: http://dx.doi.org/10.7867/1809-0354.2017v12n2p512-530

A igreja investiu estrategicamente na produção de impressos, visando aumentar sua intervenção no espaço social. Dentre os temas tratados, a educação ocupa lugar privilegiado, pois a escola, no período em questão, era um ponto de disputa.

Por meio da análise do impresso católico, proposto como fonte principal para esta análise, percebem-se diversos conflitos, em que algumas iniciativas da Igreja estão apresentadas no sentido de estabelecer novas práticas e representações, vinculadas à ideia de modernização; o que possibilita afirmar que, no campo educacional, a Igreja buscou adaptar-se ao processo de modernização como estratégia de disputa social.

Por fim, a Unitas foi um eficiente mecanismo que colaborou para estabelecer a ação católica no Rio Grande do Sul. Defendeu um ideário de educação comprometido com a recatolização do Brasil e promoveu a unificação do clero riograndense. Foi um recurso pedagógico que consolidou e divulgou uma argumentação coerente em defesa dos princípios do catolicismo para a sociedade brasileira.

\section{ADRIANA DUARTE LEON}

Professora do Instituto Federal Sul-Rio-Grandense no curso de especialização em Educação. Desenvolve pesquisas na área de Educação, com ênfase em História da Educação.

\section{REFERÊNCIAS}

AZZI, R.; GRIJP, K. V. D. História da Igreja no Brasil: ensaio e interpretação a partir do povo - terceira época: 1930-1964. Petrópolis, RJ: Vozes, 2008.

CERTEAU, M. A invenção do Cotidiano: artes de fazer. $17^{\mathrm{a}}$ ed. Rio de Janeiro: Vozes, 2011.

CHARTIER, R. (Org.). As utilizações do Objecto Impresso. Portugal: Difel - Difusão Editorial AS, 1998. I

CORSETTI, B. A. Educação - Construindo o cidadão. In: BOEIRA, N.; GOLIN, T. (Orgs.). República Velha (1889-1930). Passo Fundo: Méritos, 2007, v. 3, tomo 2 
Atos de Pesquisa em Educação - ISSN 1809-0354

Blumenau, v. 12, n.2, p.512- 530, mai./ago. 2017

DOI: http://dx.doi.org/10.7867/1809-0354.2017v12n2p512-530

(Coleção História Geral do Rio Grande do Sul).

DUTRA, E. F. Rebeldes Literários da República: história e identidade nacional do Almanaque Garnier (1903 - 1914). Belo Horizonte: Editora UFMG, 2005.

GINZBURG, C. Controlando a evidência: o juiz e o historiador. (In) NOVAIS, F. A.; SILVA, R. F. Nova história em Perspectiva. São Paulo: Cosac Naify, 2011.

LOPES, E. M. T. Da Sagrada Missão Pedagógica. São Paulo: Editora Universitária São Francisco, 2003.

LUSTOSA, O. F. Os Bispos do Brasil e a Imprensa. São Paulo: Edições Loyola, 1983.

MAGALDI, A. M. B. M. Páginas do Professorado: um estudo sobre profissão e formação docente em periódicos católicos (anos 1930 - Brasil/Portugal). Revista SíSIFO, n. 11, jan/abr. 2010.

MICELLI, S. Poder, sexo e letras na república velha. SP: Perspectiva, 1977.

MOREL, M.; BARROS, M. M. Palavra, imagem e poder: o surgimento da imprensa no Brasil do século XIX. Rio de Janeiro: DP\&A, 2003.

REVEL, J. (Org.). Jogos de Escalas: a experiência da Microanálise. Rio de Janeiro: FGV, 1998.

RUBERT, A. História da Igreja no Rio Grande do Sul: época colonial (1626 - 1822). Porto Alegre: EDIPUCRS, 1994.

SGARBI, A. D. Igreja, Educação e modernidade na década de 1930: escolanovismo católico - construído na CCBE. 1997. (Dissertação de mestrado) Pontifícia Universidade Católica de São Paulo, São Paulo.

SODRÉ, N. W. A História da Imprensa no Brasil. $2^{\mathrm{a}}$ ed. Rio de Janeiro: edições Graal, 1977.

TAMBARA, E. Estado, Igreja e Educação: Urbi et Orbe. $28^{a}$ Reunião Anual da ANPED, GT2 - História da Educação, Caxambu, 2005.

KREUTZ, L. O professor paroquial: magistério e imigração alemã. Porto Alegre: UFRGS, UFSC, EDUSC, 1991. 
Atos de Pesquisa em Educação - ISSN 1809-0354

Blumenau, v. 12, n.2, p.512- 530, mai./ago. 2017

DOI: http://dx.doi.org/10.7867/1809-0354.2017v12n2p512-530

KREUTZ, L.; KREUTZ, S. Impressos pedagógicos: afirmação do projeto republicano e contraposições (1870-1920). Revista História da Educação, n. 11, Pelotas: UFPel, 2002.

KREUTZ, L. Das Schulbuch (o livro escolar) 1917 - 1938: um periódico singular para o contexto da imprensa pedagógica no período. Revista História da Educação, n. 23, Pelotas: FaE/UFPel, set/dez 2007.

KREUTZ, L.; KUIAVA, E.; NODARI, P. C. Representação do magistério sob o movimento da restauração católica e seu reflexo nas escolas da imigração alemã no RS. Revista História UNISINOS, v. 15, n. 1, São Leopoldo: UNISINOS, 2011.

\section{ACERVOS CONSULTADOS}

Acervo da Arquidiocese de Pelotas - Jornal A Palavra

Acervo do Círculo Operário Pelotense - Jornal O Trabalho

Arquivo do Museu Sacro de Santa Maria - Boletins da Diocese

AHCMPA - Arquivo Histórico da Cúria Metropolitana de Porto Alegre - Estrella do Sul, Revista Unitas, Documentos da diocese de Uruguaiana e Documentos da arquidiocese de Porto Alegre. 